\title{
An EKF observer to estimate semi-autogenous grinding mill hold-ups ${ }^{\text {th }}$
}

\author{
J. D. le Roux ${ }^{\mathrm{a}, 1, *}$, A. Steinboeck ${ }^{\mathrm{b}}$, A. Kugi ${ }^{\mathrm{c}}$, I. K. Craig $^{\mathrm{a}}$ \\ ${ }^{a}$ Department of Electrical, Electronic and Computer Engineering, University of Pretoria, Pretoria, South Africa. \\ ${ }^{b}$ Automation and Control Institute, Vienna University of Technology, Gußhausstraße 27-29, 1040 Vienna, Austria \\ ${ }^{c}$ Christian Doppler Laboratory for Model-Based Control in the Steel Industry, Automation and Control Institute, Vienna \\ University of Technology, Gußhausstraße 27-29, 1040 Vienna, Austria
}

\begin{abstract}
A non-linear observer model of a semi-autogenous grinding mill is developed. The observer model distinguishes between the volumetric hold-up of water, solids, and the grinding media in the mill. Solids refer to all ore small enough to discharge through the end-discharge grate, and grinding media refers to the rocks and steel balls. The rocks are all ore too large to discharge from the mill. The observer model uses the accumulation rate of solids and the mill's discharge rate as parameters. It is shown that with mill discharge flow-rate, discharge density, and volumetric hold-up measurements, the model states and parameters are linearly observable. Although instrumentation at the mill discharge is not yet included in industrial circuits because of space restrictions, this study motivates the benefits to be gained from including such instrumentation. An extended Kalman filter is applied in simulation to estimate the model states and parameters from data generated by a semi-autogenous mill simulation model from literature. Results indicate that if sufficiently accurate measurements are available, especially at the discharge of the mill, it is possible to reliably estimate grinding media, solids and water hold-ups within the mill. Such an observer can be used as part of an advanced process control strategy.
\end{abstract}

Keywords: comminution, extended Kalman filter, grinding mill, observability, process control, state and parameter estimation

\section{Introduction}

Process industries in general have benefited considerably from advanced process control, but the mineral processing industry in particular has yet to take full advantage of model-based advanced process control (Craig et al., 2011). Simulation studies confirm the considerable benefits advanced model-based process control can achieve over proportional-integral-derivative (PID) control in terms of plant stability and economic performance (Pomerleau et al., 2000; Ramasamy et al., 2005; Wei and Craig, 2009a). One of the main impediments to implementing model-based control in the mineral processing industry, and specifically grinding mill circuits, is the lack of sufficient real-time measurements to estimate the necessary model states and parameters. The number of available real-time measurements are generally far less than the size of the state vector to be measured (Wei and Craig, 2009b). Therefore, the peripheral tools of the control loop such as observers and soft sensors become as important as the controller itself (Hodouin, 2011).

In general terms, the grinding performance of a mill depends on the hold-up of steel balls, ore and water. Although the total mill hold-up is generally measured in industrial circuits (Wei and Craig, 2009b), the steel ball, ore, and water hold-ups cannot be measured directly with the currently available instrumentation.

\footnotetext{
A subset of this work was presented at the 17th IFAC Symposium on Control, Optimization and Automation in Mining, Mineral and Metal Processing (Vienna, 2016) (Le Roux et al., 2016b).

${ }^{*}$ Corresponding author. Address: Department of Electrical, Electronic, and Computer Engineering, University of Pretoria, Pretoria, South Africa. Tel.: +27 12420 2201; Fax: +27 12362 5000. E-mail: derik.leroux@up.ac.za
} 
Measurement of these three mill inventories, which influence the mill's product throughput and product quality, can significantly improve plant performance if used to inform a control loop.

The model structure used to describe a comminution process has a significant impact on the success of state and parameter estimation. Models aimed at plant design are generally not suited for model-based control, and vice-versa. Steady-state phenomenological models, a combination between theoretical and empirical models, are well established and have proven valuable for comminution plant design and steadystate optimisation (King, 2001; Napier-Munn et al., 2005; Gupta and Yan, 2006). The model parameters are generally divided into the ore to be processed and the comminution unit processing the ore. Laboratory dropweight and pendulum-breakage tests provide the ore specific parameters, and sampling campaigns provide the processing unit's parameters (Napier-Munn et al., 2005). Since the characteristics of run-of-mine ore fed to industrial mills change over time, results from laboratory tests used to estimate ore specific parameters do not necessarily reflect the range of ore breakage conditions in industrial mills (Powell and Morrison, 2007). Also, sampling campaigns used to estimate the processing unit's parameters assume steady-state operation at a specific operating point, but steady-state is difficult to guarantee over a long period given the variation of run-of-mine ore characteristics. It is usually assumed the functions describing the milling environment can be expressed as simple equations with parameters that can be estimated from sampling campaign data through back-calculation. Because of the heavy reliance on back-calculation, small measurement errors can lead to large variances in parameters (Hinde and Kalala, 2009). With the advancements in computing power, computational fluid dynamics (CFD) and discrete element method (DEM) models have provided valuable insight into the charge motion of grinding processes. A difficulty associated with these fundamental models is the correct estimation of the model's parameters as ore characteristics vary over time (Morrison et al., 2007; Delaney et al., 2013). Additionally, fundamental models remain too computationally intensive to be used in advanced process control strategies (Mishra, 2003a,b).

The mathematical models of comminution processes proving most useful for industrial automatic control so far are developed on-line (Wills, 2006). These empirically derived linear time-invariant transfer function models have been successfully applied in model-based controller strategies to industrial circuits, e.g. by Hulbert et al. (1990); Craig and MacLeod (1996); Chen et al. (2007, 2008). However, these linear models are restricted to the domain around the nominal operating points of the plant and require constant management to accommodate variations in grinding conditions. System identification is particularly difficult given the inherent uncontrollable disturbances, measurement noise and high tonnage operation (Hodouin, 2011). Ideally, real-time measurements should be used to estimate model states and parameters.

Considerable work has been done to estimate grinding mill process variables using different modelling approaches (Herbst et al., 1992). A very simple model along with power and bearing pressure measurements is used by Herbst et al. (1989) to estimate mill filling and rock hardness. This work was extended in Herbst and Pate (1996) to estimate ore, water, and ball inventories. A commercialised soft-sensor is described by Herbst and Pate (1999) to estimate mill inventories and breakage rates. In all cases a Kalman filter is used to estimate the unknown state vector. Although the filters capture the qualitative trend of the unknown state vector, the studies above do not explicitly include observability analyses to ensure the filters produce reliable solutions.

A linear observability test is included in the inferential measurement work of Apelt et al. (2002). The SAG mill model of Napier-Munn et al. (2005) was used to describe the grinding process, along with a novel ball charge model and a mill-liner model. Using measurements of the mill charge weight and size-by-size solids discharge, Apelt et al. (2002) used 29 measurements to estimate 37 states and 7 parameters with an extended Kalman filter (EKF). However, the rank of the observability matrix of the linearised system was only 20, which meant a unique solution for the parameters and states was not available.

As shown by Le Roux and Craig (2016), it is theoretically possible to uniquely fit the simplified nonlinear grinding mill circuit model of Le Roux et al. (2013) to real-time plant measurements. However, the algebraic fitting procedure is too sensitive to uncertainties in measurements as the procedure involves the calculation of first and second order time-derivatives from noisy data. Although a relatively simple model is used, there are so many parameters to be defined that the value of this procedure is limited.

The model of Coetzee et al. (2010) is used by Olivier et al. (2012) to estimate the mill inventories and grinding environment parameters in simulation. Assuming measurements of the mill discharge are available, 
a dual particle filter is used to estimate the hold-up of balls, rocks, solids, fines, and water as states, and the fraction of rock entering the circuit and the power needed per tonne of fines produced as parameters. The technique achieves good quantitative estimation if constant rock abrasion rates, ball abrasion rates, and step disturbances are assumed, but these assumptions may not necessarily hold true for industrial operation.

Since the grinding performance of a mill depends on the hold-up of steel balls, ore, and water, control of these three hold-ups can reduce the variance in the throughput and quality of the mill's product. Therefore, this work aims at developing an observer for use in model-based control strategies of grinding mill circuits such that the hold-ups in the mill can be regulated (Le Roux et al., 2016a; Cortinovis et al., 2013). To achieve this aim, a non-linear observer model is presented which distinguishes between the volumetric holdup of water, solids, rocks, and balls in a SAG mill. As seen from an observability analysis, the states and parameters of this model are locally (weakly) observable, but they are not observable from the linearised observer model. The observer model is subsequently reduced such that the states and parameters are linearly observable. The measurements used by the reduced observer model are the total volumetric filling, the mill discharge flow-rate, the mill discharge density, and the derivative of the mill discharge density. Although instrumentation at the mill discharge is not yet included in industrial circuits because of space restrictions, this work motivates the benefits to be gained from including such instrumentation. To illustrate the effectiveness of the observer, a simulation study using an EKF is presented. Results indicate that the modelled states can be reliably estimated if sufficiently accurate measurements are available.

\section{Grinding mills}

\subsection{Process Description}

The open circuit SAG mill depicted in Fig. 1 receives three streams: mined ore $(M F O)$, water $(M I W)$ and additional steel balls $(M F B)$ to assist with the breakage of ore. If the mill circuit is closed with a classifier such as a hydrocyclone, the underflow from the hydrocyclone also flows into the mill. The mill charge constitutes a mixture of grinding media and slurry. Grinding media refers to the steel balls and large rocks used for breaking the ore, and slurry refers to the mixture of water and all ore material that exhibit the same flow characteristics as water. The fraction of the mill volume filled with charge is denoted by $J_{T}$.

The mill is rotated along its longitudinal axis by a motor. As shown in Fig. 2, the charge in the mill is lifted by the inner liners on the walls of the mill to a certain height from where it cascades down, only to be lifted again by the liners through the rotating action of the mill. If the rotational speed is sufficiently fast the material in the charge will become airborne after reaching the top of its travel on the mill shell. The uppermost point where material leaves the mill shell is called the shoulder of the charge. The airborne particles follow a parabolic path, reaching a maximum called the head and making contact again with the mill charge at the bottom of the mill. The cascading motion of the charge causes the ore to break through impact breakage, abrasion and attrition. The mill grind is the fraction of material in the discharge of the mill below the specification size and indicates the efficiency of the mill to break the ore. The power draw $\left(P_{\text {mill }}\right)$ of the motor turning the mill is an indication of the kinetic and potential energy imparted to the charge.

As shown in Fig. 2, the grinding media starts at the charge shoulder, continues downwards past the slurry toe, and ends at the charge toe. The slurry in the mill stretches from the slurry shoulder to the slurry toe. As slurry in the mill increases, the slurry toe approaches the charge toe. If the slurry toe and charge toe are equal, the slurry completely fills the grinding media. Up to this point, slurry discharge occurs only through the grinding media, i.e. the slurry flows through the grinding media interstices before exiting the mill. If the slurry toe exceeds the charge toe, i.e. there is more slurry than grinding media, a slurry pool forms. Discharge is no longer only via the grinding media, but also occurs via a slurry pool. Slurry pool conditions are undesirable since the pool absorbs the impact of falling material.

The ground ore in the mill mixes with the water to create a slurry. The slurry in a mill begins to form at the shoulder of the charge. The toe of the slurry starts to grow downwards towards the toe of the charge with increasing flow-rate of slurry through the mill. While the toe of the slurry is less than or equal to the toe of the charge, discharge occurs via the grinding media. When the toe of the slurry exceeds the toe of 
Table 1: Description of circuit variables assumed to be measured.

\begin{tabular}{lll}
\hline Variable & Unit & Description \\
\hline$M I W$ & $\mathrm{~m}^{3} / \mathrm{h}$ & Flow-rate of water to the mill \\
$M F O$ & $\mathrm{t} / \mathrm{h}$ & Feed-rate of ore to the mill \\
$M F B$ & $\mathrm{t} / \mathrm{h}$ & Feed-rate of steel balls to the mill \\
$J_{T}$ & - & Fraction of mill volume filled with charge \\
$Q$ & $\mathrm{~m}^{3} / \mathrm{h}$ & Mill discharge flow-rate \\
$\rho_{Q}$ & $\mathrm{t} / \mathrm{m}^{3}$ & Mill discharge density \\
$P_{\text {mill }}$ & $\mathrm{kW}$ & Mill power draw \\
\hline
\end{tabular}

the charge, a slurry pool forms at the bottom of the mill. Slurry discharge is then a combination of flow via the grinding media and the slurry pool (Latchireddi and Morrell, 2003). Slurry pool conditions should be avoided as they decrease the mill power draw and the breakage rate by cushioning material falling from the charge shoulder to the charge toe. The slurry is discharged through an end-discharge grate where the aperture size of the end-discharge grate limits the particle size of the discharged slurry. The flow-rate of slurry at the mill discharge is given by $Q$. It is assumed that the in-mill slurry density is equal to the discharge slurry density $\left(\rho_{Q}\right)$. The circuit variables are described in Table 1.

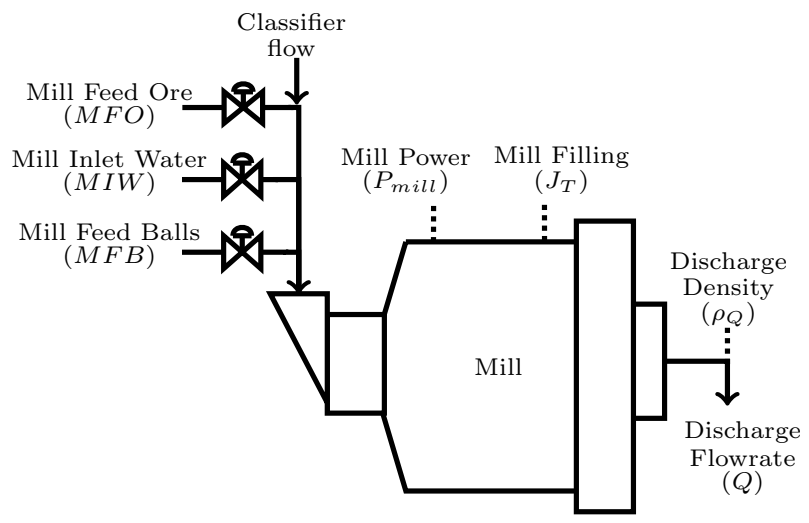

Figure 1: A semi-autogenous grinding mill.

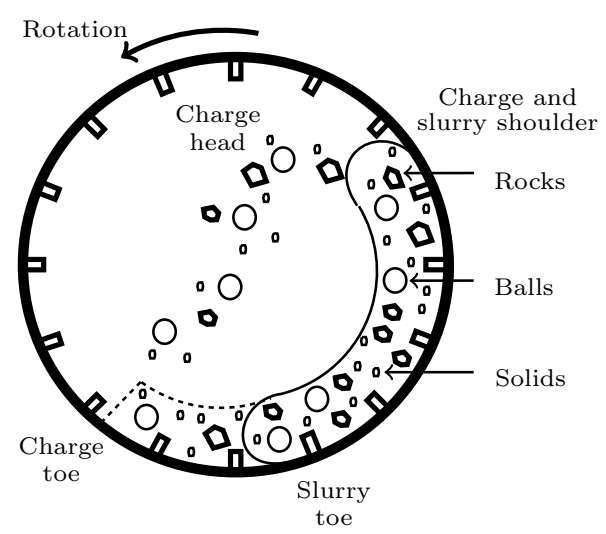

Figure 2: Cross-section of a semi-autogenous grinding mill. 


\subsection{Industrial Circuit Measurements}

The survey of Wei and Craig $(2009 \mathrm{~b})$ indicates that $P_{\text {mill }}$ and $J_{T}$ are commonly measured variables in industrial plants, whereas $Q$ and $\rho_{Q}$ are not explicitly included as real-time measured variables for any of the plants surveyed.

The combined mass of the mill and of the charge inside the mill is generally measured using either load cells or bearing pressure. Because this is not a direct measurement of $J_{T}$, the relation between $J_{T}$ and a mass measurement needs to be determined whenever a mill survey is performed (Powell and Mainza, 2006). For different mill charges, accurate mill filling measurements after mill stops can be used to calibrate the relationship between the mass measurement and $J_{T}$. The calibration exercise should be repeated at reasonable intervals as the loss of liner mass through wear and tear will cause a drift in the accuracy of the relationship. Once the drift in the data is quantified, an empirical liner wear model can be constructed to predict the service life of liners and adjust the relationship between the mass measurement and $J_{T}$ over time. With careful planning, the mass to $J_{T}$ relationship can easily be checked within half an hour from mill stop to start (Powell et al., 2009).

This study assumes measurements of $Q$ and $\rho_{Q}$ are available. Because of space restrictions at the discharge trommel of the mill, inclusion of flow and density instrumentation at the mill discharge is not yet a viable reality (Napier-Munn et al., 2005). Through careful planning and design of greenfield comminution circuits it should be possible to install existing flow and density instrumentation at a mill discharge trommel. In the case where the mill discharges into a sump, $\rho_{Q}$ and $Q$ can be back-calculated from a flow-balance if all other inflows and outflows are measured, but this is sensitive to the accuracy of measurements at the sump. This study aims to illustrate the benefits to be gained from including $Q$ and $\rho_{Q}$ measurement instrumentation in industrial circuits.

SAG mills are usually designed with a constant target fractional volumetric filling of balls $\left(J_{B}\right)$ in mind. Because accurate real-time measurements of $J_{B}$ are not available, $J_{B}$ is usually not included in control schemes to manipulate the mill grind and the discharge rate. Although $J_{B}$ is not measured directly, it can be approximated inferentially using models and measurements of $P_{\text {mill }}$ or $J_{T}$ (Apelt et al., 2001). Generally a linear relationship between the rock volume and ball abrasion rate is assumed. This assumption allows for the calculation of $M F B$ to maintain an approximately constant $J_{B}$ in terms of the ton of ore milled. At steady-state this relates to $M F B$ being a constant fraction of $M F O$.

\section{Observer Model for a Grinding Mill}

This section describes how the observer model is developed. The aim of the observer is to use the variables listed in Table 1 as measured quantities to estimate the mill states, the discharge rate constant, and the ore and ball breakage rates. The nomenclature for the observer model is given in Table 2 .

The constituents in the mill are modelled as four volumetric quantities: water $\left(x_{w}\right)$, solids $\left(x_{s}\right)$, rocks $\left(x_{r}\right)$, and balls $\left(x_{b}\right)$. The model makes use of only two size classes to describe ore in the mill: solids includes all ore smaller than the end-discharge grate aperture size, and rocks all ore larger than the aperture size.

\subsection{Process Dynamics}

\subsubsection{Process Feed}

The mill inflow flow-rates are described as

$$
\begin{aligned}
V_{w i} & =M I W+V_{c w} \\
V_{s i} & =M F O\left(1-\alpha_{r}\right) / \rho_{o}+V_{c s} \\
V_{r i} & =\alpha_{r} M F O / \rho_{o} \\
V_{b i} & =M F B / \rho_{b},
\end{aligned}
$$

where $V_{w i}, V_{s i}, V_{r i}$, and $V_{b i}\left(\mathrm{~m}^{3} / \mathrm{h}\right)$ are the mill inflow of water, solids, rocks, and balls respectively, $\rho_{o}$ $\left(\mathrm{t} / \mathrm{m}^{3}\right)$ is the density of the feed ore, $\rho_{b}\left(\mathrm{t} / \mathrm{m}^{3}\right)$ is the density of the steel balls, and $V_{c w}$ and $V_{c s}\left(\mathrm{~m}^{3} / \mathrm{h}\right)$ are the flow of water and solids returned by the classifier, respectively. The parameter $\alpha_{r}$ defines the mass 
Table 2: Observer model nomenclature

\begin{tabular}{lll}
\hline Parm & Unit & Description \\
\hline$\alpha_{r}$ & - & Mass fraction of rocks in the feed ore \\
$\rho_{b}$ & $\mathrm{t} / \mathrm{m}^{3}$ & Density of steel balls \\
$\rho_{o}$ & $\mathrm{t} / \mathrm{m}^{3}$ & Density of feed ore \\
$\rho_{w}$ & $\mathrm{t} / \mathrm{m}^{3}$ & Density of water \\
$\eta$ & $\mathrm{h}^{-1} \mathrm{~m}^{-3}$ & Discharge rate per volume of slurry \\
$K_{b}$ & $1 / \mathrm{h}$ & Ball abrasion rate \\
$K_{r}$ & $1 / \mathrm{h}$ & Rock abrasion rate \\
$v_{m i l l}$ & $\mathrm{~m}^{3}$ & Mill volume \\
$x_{b}$ & $\mathrm{~m}^{3}$ & Volume of balls in the mill \\
$x_{r}$ & $\mathrm{~m}^{3}$ & Volume of rocks in the mill \\
$x_{s}$ & $\mathrm{~m}^{3}$ & Volume of solids in the mill \\
$x_{w}$ & $\mathrm{~m}^{3}$ & Volume of water in the mill \\
\hline
\end{tabular}

fraction of rocks in $M F O$ and is assumed to be measured as a function of time (Wei and Craig, 2009b). The implicit assumption when dividing by $\rho_{o}$ in (1b) and (1c) is that the ore is non-porous. It is assumed that the flow from the classifier to the mill is known.

\subsubsection{Population Balance}

The population balance used to describe the kinetics of the states defined above is

$$
\begin{aligned}
\dot{x}_{w} & =V_{w i}-V_{w o} \\
\dot{x}_{s} & =V_{s i}-V_{s o}+R C \\
\dot{x}_{r} & =V_{r i}-R C \\
\dot{x}_{b} & =V_{b i}-B C,
\end{aligned}
$$

where $V_{w o}$ and $V_{s o}\left(\mathrm{~m}^{3} / \mathrm{h}\right)$ are the discharge of water and solids from the mill respectively, and $R C$ and $B C$ $\left(\mathrm{m}^{3} / \mathrm{h}\right)$ are the consumption of rocks and balls respectively. Because the mill is fitted with an end-discharge grate, no rocks or balls are discharged from the mill. It is assumed the mill is a fully mixed reactor. The rate of ball consumption is considerably lower than for rocks, and its contribution to $\dot{x}_{s}$ is regarded as negligible.

\subsubsection{Breakage Rates}

The cumulative rates modelling approach assumes only one function is necessary to describe the grinding kinetics. The cumulative breakage rate function is defined as the rate per unit mass that a given species coarser than a given size breaks to below that size (Le Roux and Craig, 2013). This is an advantage over other population balance models which require two functions, a breakage rate and an appearance function, to describe grinding kinetics (Whiten, 1974). The cumulative breakage rates modelling approach was used by Austin et al. (1993) to model the steady-state behaviour and by Amestica et al. $(1993,1996)$ to model the dynamic behaviour of SAG mills. A disadvantage of this approach is that the cumulative rate of breakage of ore above a given size $s_{i}$ is assumed to be unaffected by the grinding environment and the detailed structure of the size distribution above $s_{i}$. Empirical relationships are required to relate the parameters of the cumulative breakage rate function to variations in the milling environment. However, more sophisticated models face similar problems where the parameters of both the breakage rate and breakage distribution function vary according to changes in the grinding environment (Hinde and Kalala, 2009). The cumulative breakage rate function remains constant if the ball filling level and the charge level remain relatively constant (Amestica et al., 1993). A validation study of the cumulative rates model was conducted by Salazar et al. (2009), and a model predictive controller using the cumulative rates model was investigated in simulation by Salazar et al. (2014). 
Similar to the cumulative rates modelling approach, the consumption of rocks $(R C)$ and balls $(B C)$ in the population balance of $(2 \mathrm{~b})$ to $(2 \mathrm{~d})$ are described as

$$
\begin{aligned}
& R C=x_{r} K_{r} \\
& B C=x_{b} K_{b},
\end{aligned}
$$

where $K_{r}$ and $K_{b}(1 / \mathrm{h})$ are the abrasion rates of rocks and balls, respectively. Instead of the first order approach above, a second order model could be used to describe $R C$ as the interaction between rocks and rocks, balls and rocks, and rocks and liners. However, this is deemed as an unnecessary increase in the number of model parameters as the first order cumulative rates modelling approach is well attested in literature and practice (Amestica et al., 1993, 1996; Hinde and Kalala, 2009; Salazar et al., 2009, 2014).

A relatively constant rock abrasion rate $K_{r}$ can be achieved through a high $x_{b}$ (as in the case of a ball mill), but the heavy balls increase the power required to turn the mill and consequently increase the energy costs. The ball abrasion rate $K_{b}$ depends on the ore characteristics, the mill liner type, the ball material, $x_{r}$, and $x_{b}$. A high $x_{b}$ increases $K_{b}$ as there is more ball-ball and ball-liner contact rather than ball-ore contact. Although a low $x_{b}$ reduces $K_{b}$, it also reduces the grinding ability of the mill. For a very high mill rotational rate the balls may collide with exposed liners causing unnecessary liner wear and a higher $K_{b}$.

\subsubsection{Mill Discharge}

The mill discharge model for the observer is adapted from the model presented in Morrell and Stephenson (1996), where the discharge of charge from the mill through the end-discharge grate is viewed as a product of two mechanisms: the fluid transport through the grate, and the solids classification by the grate which differentiates between ground particles either returning to the milling chamber for further grinding or becoming part of the mill discharge stream. In the case of $i=1,2, \ldots, N$ ore size classes, the discharge rate $\left(d_{i}\right)\left(\mathrm{h}^{-1}\right)$ of the mill charge is approximated as (Morrell, 2004)

$$
\begin{array}{ll}
d_{i}=d_{0} & ; \quad s_{i} \leq s_{m} \\
d_{i}=d_{0} \frac{\ln s_{i}-\ln s_{g}}{\ln s_{m}-\ln s_{g}} & ; \quad s_{m}<s_{i} \leq s_{g} \\
d_{i}=0 & ; \quad s_{i}>s_{g},
\end{array}
$$

where $s_{i}(\mathrm{~mm})$ represents the particle size classes, $d_{0}\left(\mathrm{~h}^{-1}\right)$ is the specific discharge rate for water and ore up to particle size $s_{m}(\mathrm{~mm})$ (i.e. slurry), and $s_{g}(\mathrm{~mm})$ is the effective mesh size of the grate above which discharge is zero. Since rocks and balls are larger than $s_{g}$, they have a discharge rate of $0 \mathrm{~h}^{-1}$.

To determine $d_{0}$, a function relating slurry hold-up to slurry flow (i.e. flow of particles smaller than $s_{m}$ exhibiting the same flow characteristics as water) out of the mill is required. This function should account for whether the slurry flow occurs via the grinding media or via a slurry pool. The slurry flowing through a single grate aperture depends on the following factors: area of the aperture, depth of the aperture below the free surface of the slurry, gravity and centrifugal forces, and slurry viscosity. By analysing pilot and industrial mills, Morrell and Stephenson (1996) expressed the relationship between slurry flow-rate and hold-up for the case where slurry flow occurs via the grinding media and for the case where slurry flow occurs via the slurry pool.

As discussed in Section 2.1, slurry flow via the grinding media occurs when $J_{p} \leq J_{\max }$ and via the slurry pool when $J_{p}>J_{\max }$. Here $J_{p}$ is the fraction of the mill volume filled with slurry, $J_{\max }=0.5 J_{T}-J_{p o}$ is the maximum volumetric fraction of the interstices of the grinding media which can be filled with slurry, $J_{p o}=0.33\left(1-\bar{r}_{a}\right)$ is the fraction of "dead" slurry hold-up within the mill (contained between the mill shell and the outer most grate aperture), and $\bar{r}_{a}(\mathrm{~m})$ is the radial position of the outermost row of grate apertures as a fraction of the mill radius $r_{m}$.

Slurry flow via the grinding media $Q_{m}\left(\mathrm{~m}^{3} / \mathrm{h}\right)$ is expressed as (Morrell and Stephenson, 1996)

$$
Q_{m}=k_{m} J_{p m}^{2} \lambda^{2.5} D_{m}^{0.5} A \phi_{c}^{-1.38}
$$

where $k_{m}\left(\mathrm{~m}^{0.5} / \mathrm{h}\right)$ is a constant, $J_{p m}$ is the net fractional slurry hold-up in the grinding media, $D_{m}(\mathrm{~m})$ is the mill diameter, $A\left(\mathrm{~m}^{2}\right)$ is the total open area of the grate apertures, $\phi_{c}$ is the fraction of the critical mill 
speed. The mean relative radial position of the grate apertures is defined as $\lambda=\frac{\sum r_{i} a_{i}}{r_{m} \sum a_{i}}$ where $a_{i}$ is the open area of all holes at a radial position $r_{i}$. Slurry flow via the slurry pool $Q_{t}\left(\mathrm{~m}^{3} / \mathrm{h}\right)$ is expressed as

$$
Q_{t}=k_{t} J_{p t} \lambda^{2} D_{m}^{0.5} A
$$

where $J_{p t}=J_{p}-J_{\max }$ is the net fractional hold-up of slurry in the slurry pool, and $k_{t}\left(\mathrm{~m}^{0.5} / \mathrm{h}\right)$ is a constant.

It is worth noting the inverse relationship between $\phi_{c}$ and $Q_{m}$ shown in (5). A possible reason for this relationship is the increase in the dynamic porosity (void fraction) of the charge as the mill speed increases (Latchireddi and Morrell, 2003). Also, the grinding media thrown from the charge shoulder overshoots the charge toe because of the higher speed. As a result of the overshoot the number of high impact breakage events reduces and consequently the fines contributing to the mill slurry reduce. Morrell and Stephenson (1996) assumed the viscosity effects would be captured by the constants $k_{m}$ and $k_{t}$ without altering the form of (5) and (6).

Solids between sizes $s_{m}$ and $s_{g}$ also exit the mill and contribute approximately $5-15 \%$ to the volumetric flow-rate depending on the size of the grates. To predict the total flow-rate of slurry out of the mill $Q$, the predictions for $Q_{m}$ and $Q_{t}$ need to be increased to account for the additional amount of coarse material. Therefore

$$
Q=k_{g}\left(Q_{m}+Q_{t}\right),
$$

where $k_{g}$ is a positive dimensionless factor to account for coarse material. The value of $k_{g}$ varies depending on the grate aperture size. Morrell and Stephenson (1996) provide guidelines on the choice of $k_{g}$.

In the inferential measurement work of Apelt et al. (2002), it is assumed that no slurry pooling occurs in the case of a large open area $(A)$, a high relative radial position of the open area $(\lambda)$, and a high relative radial position of the outermost apertures $\left(\bar{r}_{a}\right)$ in the end-discharge grate. For this study it was assumed that the discharge flow is only through the grinding media, i.e. $Q=k_{g} Q_{m}$. Therefore, assuming no slurry pooling, $Q$ can be approximated as (Kojovic et al., 2011)

$$
Q=k_{g} k_{m} \lambda^{2.5} D_{m}^{0.5} A \phi_{c}^{-1.38} J_{p m}^{2} \text {. }
$$

As shown in (8), $Q$ is quadratically proportional to $J_{p m}$ if there is no slurry pool. Thus, in terms of the four states of the observer defined $\left(x_{w}, x_{s}, x_{r}\right.$, and $\left.x_{b}\right)$, it is possible to express $Q$ as

$$
Q=\eta\left(x_{w}+x_{s}\right)^{2}
$$

where $\left(x_{w}+x_{s}\right)$ represents the total slurry hold-up in the mill, and $\eta\left(\mathrm{h}^{-1} \mathrm{~m}^{-3}\right)$ is the discharge rate per volume of slurry. Since only two size classes are used for the observer model, one size which discharges completely and one which remains inside the mill, it is implicitly assumed in (9) that $s_{g}=s_{m}$ in (4). Therefore, the discharge of the water $\left(V_{w o}\right)$ and solids $\left(V_{s o}\right)$ in $(2 \mathrm{a})$ and $(2 \mathrm{~b})$ can be expressed as

$$
\begin{aligned}
& V_{w o}=\eta\left(x_{w}+x_{s}\right) x_{w} \\
& V_{s o}=\eta\left(x_{w}+x_{s}\right) x_{s} .
\end{aligned}
$$

\subsection{Process Output}

For this study, it is assumed that measurements of $J_{T}, Q$ and $\rho_{Q}$ are available. The implications of measuring these variables are discussed in Section 2.2. These quantities are modelled as

$$
\begin{aligned}
J_{T} & =\frac{x_{w}+x_{s}+x_{r}+x_{b}}{v_{\text {mill }}} \\
Q & =\eta\left(x_{w}+x_{s}\right)^{2} \\
\rho_{Q} & =\frac{\rho_{o} x_{s}+\rho_{w} x_{w}}{x_{s}+x_{w}} .
\end{aligned}
$$

The fourth measured output listed in Table 1 is $P_{\text {mill }}(\mathrm{kW})$, which is defined by Apelt et al. (2001) as

$$
P_{\text {mill }}=P_{N L}+k_{P} P_{C}
$$


where $P_{N L}(\mathrm{~kW})$ is the no-load power (empty mill power draw), $P_{C}(\mathrm{~kW})$ is the mill power draw attributed to the mill contents, and $k_{P}$ is a lumped power draw parameter to account for heat losses due to internal friction, energy for attrition and abrasion breakage and rotation of grinding media, plus inaccuracies associated with the assumptions and measurements of the charge shape and motion (Napier-Munn et al., 2005).

Apelt et al. (2001) models $P_{C}$ as an empirical function of $J_{T}$ and the mill charge density $\left(\rho_{C}\right)$

$$
\rho_{C}=\frac{\rho_{b} x_{b}+\rho_{o}\left(x_{r}+x_{s}\right)+\rho_{w} x_{w}}{x_{b}+x_{r}+x_{s}+x_{w}} .
$$

Ideally $\rho_{C}$ could be inferred from the measurement of $P_{\text {mill }}$ using the power draw model in Apelt et al. (2001). However, to use the model, parameter $k_{P}$ in (12) must be fitted to process data. This fitting process requires $\rho_{C}$ to be known. Therefore, the observer model does not make use of $P_{m i l l}$ as an output equation as it only introduces additional parameters to estimate. The same holds true for other models of $P_{\text {mill }}$, such as for example the models in Austin (1990) and Le Roux et al. (2013).

\section{Observability of States and Parameters}

\subsection{Background}

A multi-input-multi-output control-affine non-linear state-space model with $\operatorname{dim}(x)=n \operatorname{and} \operatorname{dim}(y)=m$ can be written as

$$
\begin{aligned}
\dot{x} & =f(x)+g(x) u \\
y & =h(x) .
\end{aligned}
$$

The system in (14) is said to be locally (weakly) observable at $x_{0}$ if there exists a neighbourhood $X_{0}$ of $x_{0}$ such that for every $x_{1}$ which is an element of the neighbourhood $X_{1} \subset X_{0}$ of $x_{0}$ the indistinguishability of the states $x_{0}$ and $x_{1}$ implies that $x_{0}=x_{1}$. The two states $x_{1}$ and $x_{0}$ are said to be indistinguishable if for every admissible input $u$ the output $y$ of (14) for the initial state $x_{0}$ and for the initial state $x_{1}$ is identical. If the system satisfies the so called observability rank condition, i.e. the observability codistribution of $x_{0}$ (Hermann and Krener, 1977)

$$
d \mathcal{O}=\operatorname{span}\left\{\mathrm{d} h_{j}, \mathrm{~d} L_{f} h_{j}, \ldots, \mathrm{d} L_{f}^{n-1} h_{j}\right\} ; j=1, \ldots, m
$$

has dimension $n$ at $x_{0}$, then the system is locally (weakly) observable. Note, $L_{f}^{k} h_{j}$ refers to the $k$-th repeated Lie derivative of the scalar function $h_{j}(x)$ along the vector field $f(x)$, and $\mathrm{d}$ is the exterior derivative. In the linear case, the observability codistribution corresponds to the observability matrix $\mathcal{O}^{T}=\left[C^{T}, A^{T} C^{T}, \ldots,\left(A^{n-1}\right)^{T} C^{T}\right]$ where $C=\left.\frac{\partial h}{\partial x}\right|_{x=x_{0}}$ and $A=\left.\frac{\partial}{\partial x}(f(x)+g(x) u)\right|_{x=x_{0}, u=u_{0}}$.

\subsection{Analysis of Observer Model}

For the observer model of the grinding mill, it is assumed that the parameters $\eta, K_{r}$ and $K_{b}$ are unknown constants, although in practice these parameters may vary slowly. Thus, the observer model described in Section 3 can be written in the form of (14), such that

$$
\left.\begin{array}{rl}
\dot{x}=f_{O}(x)+g_{O}(x) u & =\left[\begin{array}{l}
-\eta\left(x_{w}+x_{s}\right) x_{w} \\
-\eta\left(x_{w}+x_{s}\right) x_{s}+x_{r} K_{r} \\
-x_{r} K_{r} \\
-x_{b} K_{b} \\
0_{3 \times 1}
\end{array}\right]+\left[\begin{array}{l}
I_{4 \times 4} \\
0_{3 \times 4}
\end{array}\right] u \\
y=h_{O}(x) \quad
\end{array}\right]\left[\begin{array}{l}
\left.J_{T}, Q, \rho_{Q}\right]^{T}
\end{array}\right.
$$

where $x=\left[x_{w}, x_{s}, x_{r}, x_{b}, \eta, K_{r}, K_{b}\right]^{T}, u=\left[V_{w i}, V_{s i}, V_{r i}, V_{b i}\right]^{T}$ and $y=h_{O}(x)$ is given by (11). (The subscript $O$ refers to Observer.) 
For the system in (16), the dimension of the observability codistribution $d \mathcal{O}$ was determined using Maple ${ }^{1}$. The dimension of $d \mathcal{O}$ at a generic point $x_{0}$ is 7 , which implies that the non-linear system is locally (weakly) observable. Thus, a non-linear observer such as a moving horizon estimator (MHE) could possibly estimate the unknown states and parameters. However, it is necessary to correctly assume the time-varying nature of the parameters for the MHE to estimate the true state and parameter values. A longer time horizon for the MHE reduces the validity of modelling the parameters as constants, but a shorter time horizon may not include sufficient system dynamics for the observer to estimate the unknown states and parameters.

Linearisation of (16) results in the $A$ and $C$ matrices

$$
\begin{aligned}
& A=\left[\begin{array}{ccccccc}
-\eta\left(2 x_{w}+x_{s}\right) & -\eta x_{w} & 0 & 0 & -\left(x_{w}+x_{s}\right) x_{w} & 0 & 0 \\
-\eta x_{s} & -\eta\left(x_{w}+2 x_{s}\right) & K_{r} & 0 & -\left(x_{w}+x_{s}\right) x_{s} & x_{r} & 0 \\
0 & 0 & -K_{r} & 0 & 0 & -x_{r} & 0 \\
0 & 0 & 0 & -K_{b} & 0 & 0 & -x_{b} \\
0_{3 \times 1} & 0_{3 \times 1} & 0_{3 \times 1} & 0_{3 \times 1} & 0_{3 \times 1} & 0_{3 \times 1} & 0_{3 \times 1}
\end{array}\right] \\
& C=\left[\begin{array}{cccccc}
\frac{1}{v_{m i l l}} & \frac{1}{v_{\text {mill }}} & \frac{1}{v_{\text {mill }}} & \frac{1}{v_{\text {mill }}} & 0 & 0 \\
2 \eta\left(x_{w}+x_{s}\right) & 2 \eta\left(x_{w}+x_{s}\right) & 0 & 0 & \left(x_{w}+x_{s}\right)^{2} & 0_{1 \times 2} \\
\frac{\rho_{w}-\rho_{Q}}{x_{w}+x_{s}} & \frac{\rho_{o}-\rho_{Q}}{x_{w}+x_{s}} & 0 & 0 & 0 & 0 \\
1 \times 2
\end{array}\right] .
\end{aligned}
$$

The observability matrix $\mathcal{O}$ formed from (17) has rank 5 . From an analysis of the eigenvalues and eigenvectors of the matrix $A$ it can be seen that the three unknown parameters $\left(\eta, K_{r}, K_{b}\right)$ each contribute an integral mode to the linearised system. Because of this repeated mode, two of the three parameters need to be chosen in the linearised model for the other parameter to be linearly observable.

In an attempt to attain linear observability of the system, the time derivatives of (16b) can be used as additional measurements. However, the addition of $\dot{J}_{T}, \dot{Q}$, or $\dot{\rho}_{Q}$, or all of these derivatives only increases the rank of the observability matrix $\mathcal{O}$ from 5 to 6 . To achieve full column rank, the measurement $\rho_{C}$ needs to be used along with $\dot{Q}$, or $\dot{\rho}_{Q}$, or both. However, direct measurement of $\rho_{C}$ is rarely possible. If $\rho_{C}$ is estimated from $P_{\text {mill }}$, additional unknown parameters are introduced which negates any benefit of using $\rho_{C}$ as an inferred measured variable.

\subsection{Model Reduction and Linear Observability}

\subsubsection{Reduced Model}

To achieve linear observability, the model in (16) is reduced based on the assumption that the dynamics of the slurry $\left(x_{w}\right.$ and $\left.x_{s}\right)$ is much faster than the dynamics of the grinding media $\left(x_{r}\right.$ and $\left.x_{b}\right)$. Therefore,

$$
\begin{gathered}
\dot{x}=f_{R M}(x)+g_{R M}(x) u=\left[\begin{array}{l}
-\eta\left(x_{w}+x_{s}\right) x_{w} \\
-\eta\left(x_{w}+x_{s}\right) x_{s}+\chi \\
0_{3 \times 1}
\end{array}\right]+\left[\begin{array}{l}
I_{2 \times 2} \\
0_{3 \times 2}
\end{array}\right] u \\
y=h_{R M}(x, u)=\left[\begin{array}{l}
\frac{x_{w}+x_{s}+x_{r b}}{v_{m i l l}} \\
\eta\left(x_{w}+x_{s}\right)^{2} \\
\frac{\rho_{o} x_{s}+\rho_{w} x_{w}}{x_{s}+x_{w}} \\
\frac{\left(\rho_{o}-\rho_{w}\right)\left(\chi x_{w}+x_{w} V_{s i}-x_{s} V_{w i}\right)}{\left(x_{s}+x_{w}\right)^{2}}
\end{array}\right]
\end{gathered}
$$

where $x=\left[x_{w}, x_{s}, x_{r b}, \eta, \chi\right]^{T}, u=\left[V_{w i}, V_{s i}\right]^{T}$, and $y=\left[J_{T}, Q, \rho_{Q}, \dot{\rho}_{Q}\right]^{T}$. (The subscript $R M$ refers to Reduced Model.) The state $x_{r b}\left(\mathrm{~m}^{3}\right)$ represents all grinding media in the mill (sum of rocks and balls) which is assumed to stay relatively constant compared to $x_{w}$ and $x_{s}$, and the state $\chi\left(\mathrm{m}^{3} / \mathrm{h}\right)$ represents the generation of solids. The output vector in (11) is extended in (18b) with the addition of $\dot{\rho}_{Q}$.

\footnotetext{
${ }^{1}$ Maple $^{T M}$ is a trademark of Waterloo Maple Inc.
} 


\subsubsection{Linear Observability}

The $A$ and $C$ matrices for the system in (18) are

$$
\begin{aligned}
& A=\left[\begin{array}{ccccc}
-\eta\left(2 x_{w}+x_{s}\right) & -\eta x_{w} & 0 & -\left(x_{w}+x_{s}\right) x_{w} & 0 \\
-\eta x_{s} & -\eta\left(x_{w}+2 x_{s}\right) & 0 & -\left(x_{w}+x_{s}\right) x_{s} & 1 \\
0_{3 \times 1} & 0_{3 \times 1} & 0_{3 \times 1} & 0_{3 \times 1} & 0_{3 \times 1}
\end{array}\right] \\
& C=\left[\begin{array}{ccccc}
\frac{1}{v_{m i l l}} & \frac{1}{v_{m i l l}} & \frac{1}{v_{\text {mill }}} & 0 & 0 \\
2 \eta\left(x_{w}+x_{s}\right) & 2 \eta\left(x_{w}+x_{s}\right) & 0 & \left(x_{w}+x_{s}\right)^{2} & 0 \\
\frac{\rho_{w}-\rho_{Q}}{x_{w}+x_{s}} & \frac{\rho_{o}-\rho_{Q}}{x_{w}+x_{s}} & 0 & 0 & 0 \\
\frac{\left(\rho_{o}-\rho_{w}\right)\left(\chi+V_{s i}\right)}{\left(x_{w}+x_{s}\right)^{2}}-\frac{2 \dot{\rho}_{Q}}{x_{w}+x_{s}} & \frac{\left(\rho_{w}-\rho_{o}\right) V_{w w}}{\left(x_{w}+x_{s}\right)^{2}}-\frac{2 \dot{\rho}_{Q}}{x_{w}+x_{s}} & 0 & 0 & \frac{\left(\rho_{o}-\rho_{w}\right) x_{w}}{\left(x_{w}+x_{s}\right)^{2}}
\end{array}\right] .
\end{aligned}
$$

The observability matrix $\mathcal{O}$ of the pair $(C, A)$ has full column rank. Therefore, all states and parameters are observable from the system outputs. However, at steady-state, $\dot{\rho}_{Q}$ will be equal to zero and the observability matrix $\mathcal{O}$ will no longer have full column rank. (The determinant of the first 5 rows and columns is $\operatorname{det}\left(\mathcal{O}_{1 . .5,1 . .5}\right)=\left(\rho_{o}-\rho_{w}\right) \dot{\rho}_{Q} / v_{\text {mill }}^{2}$ which reduces to zero at steady-state. $)$ For a reasonable value of $\dot{\rho}_{Q}$ it is necessary to continuously excite the system.

As seen in (18b), the derivative of $\rho_{Q}$ is used as a fourth measurement. This is necessary to achieve linear observability. If $\dot{J}_{T}$ is used instead of $\dot{\rho}_{Q}$ in (18b), the observability matrix $\mathcal{O}$ does not have full column rank. Although $\dot{Q}$ could be used to achieve full column rank, it is a function of $\dot{\eta}$ which is assumed to be equal to zero in (18a). Rather than including the assumption that $\dot{\eta}=0$ in the measurement model, $\dot{\rho}_{Q}$ is used in (18b).

\section{Observer Design}

The trapezoidal rule is used to discretize the reduced observer model presented in continuous-time form in (18). A discrete-time EKF is used as the non-linear estimator (Simon, 2006). The system and measurement equations are

$$
\begin{aligned}
& x_{k}=F_{k-1}\left(x_{k-1}, u_{k-1}, w_{k-1}\right) \\
& y_{k}=H_{k}\left(x_{k}, u_{k}, v_{k}\right) \\
& w_{k} \sim\left(0, Q_{k}\right) ; v_{k} \sim\left(0, R_{k}\right),
\end{aligned}
$$

where the process noise $w_{k}$ is white noise with covariance $Q_{k}>0$ and the measurement noise $v_{k}$ is white noise with covariance $R_{k}>0$.

Between each measurement, the state estimate $\hat{x}_{k}$ and the estimation-error covariance matrix $P_{k}$ is propagated according to the known non-linear dynamics of the system:

$$
\begin{aligned}
\hat{x}_{k}^{-} & =F_{k-1}\left(\hat{x}_{k-1}^{+}, u_{k-1}, 0\right) \\
P_{k}^{-} & =T_{k-1} P_{k-1}^{+} T_{k-1}^{T}+L_{k-1} Q_{k-1} L_{k-1}^{T}
\end{aligned}
$$

where $T_{k-1}=\left.\frac{\partial F_{k-1}}{\partial x_{k-1}}\right|_{\hat{x}_{k-1}^{+}, u_{k-1}, 0}$ and $L_{k-1}=\left.\frac{\partial F_{k-1}}{\partial w_{k-1}}\right|_{\hat{x}_{k-1}^{+}, u_{k-1}, 0}$. The state estimate and its covariance is updated through

$$
\begin{aligned}
& K_{k}=P_{k}^{-} S_{k}^{T}\left(S_{k} P_{k}^{-} S_{k}^{T}+R_{k}\right)^{-1} \\
& \hat{x}_{k}^{+}=\hat{x}_{k}^{-}+K_{k}\left[y_{k}-H_{k}\left(\hat{x}_{k}^{-}, u_{k}, 0\right)\right] \\
& P_{k}^{+}=\left(I-K_{k} S_{k}\right) P_{k}^{-}
\end{aligned}
$$

where $S_{k}=\left.\frac{\partial H_{k}}{\partial x_{k}}\right|_{\hat{x}_{k}^{-}, u_{k}, 0}$.

\section{Simulation}

\subsection{Simulation Setup}

The aim of the simulation is to test the effectiveness of the reduced observer model to be used in a state and parameter estimation scheme. The simulation setup is depicted in Fig. 3. The plant, a SAG mill with 


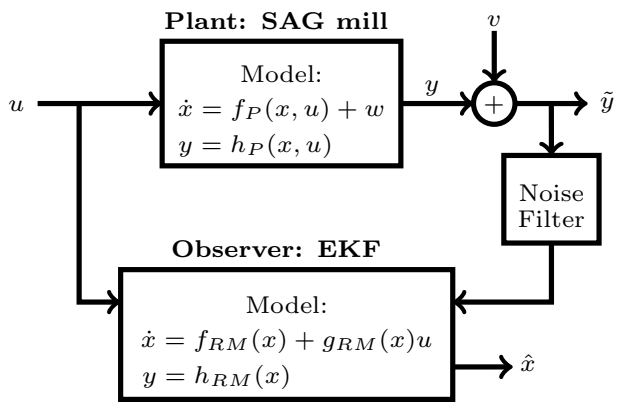

Figure 3: Simulation setup.

an end-discharge grate, is represented by the continuous-time dynamic non-linear model of Le Roux et al. (2013), and the power-draw is given by the model of Apelt et al. (2001). This model is used to simulate the system and to generate fictitious measurement data. The noisy measurement data is filtered using a Savitzky-Golay filter, which is also used to determine the derivative $\dot{\rho}_{Q}$ (Savitzky and Golay, 1964).

\subsubsection{Plant model}

The SAG mill simulation model of Le Roux et al. (2013) was developed with the aim to produce reasonably accurate model responses using as few parameters and states as possible. The model was validated using industrial plant data. The model divides the ore into the same two size classes as used in the observer model. Therefore, the mill inflow flow-rates are the same as in (1), and the population balance of the model is the same as in (2).

The mill discharge flow-rates are defined as

$$
\begin{aligned}
V_{w o_{P}} & =\varphi d_{H} x_{w}\left(\frac{x_{w}}{x_{s}+x_{w}}\right) \\
V_{s o_{P}} & =\varphi d_{H} x_{w}\left(\frac{x_{s}}{x_{s}+x_{w}}\right),
\end{aligned}
$$

where $d_{H}(1 / \mathrm{h})$ is a constant discharge rate parameter, and $\varphi$ is an empirical function called the rheology factor. (The subscript $P$ refers to Plant.) The rheology factor attempts to incorporate the effect of the fluidity and density of the slurry on the performance of the milling circuit and is defined as

$$
\varphi=\left[\max \left(0,1-\left(\frac{1}{\varepsilon_{s v}}-1\right) \frac{x_{s}}{x_{w}}\right)\right]^{0.5},
$$

where $\varepsilon_{s v}$ is the maximum fraction of solids by volume of slurry at zero slurry flow. A rheology factor of unity corresponds to $\frac{x_{s}}{x_{w}}=0$, indicating the slurry consists only of water. A rheology factor of zero corresponds to $\frac{x_{s}}{x_{w}}=\frac{\varepsilon_{s v}}{1-\varepsilon_{s v}}$, indicating the slurry is a non-flowing mud.

The rock consumption $\left(R C_{P}\right)$ and ball consumption $\left(B C_{P}\right)$ for the plant model are defined as

$$
\begin{aligned}
R C_{P} & =\frac{\varphi P_{\text {mill }} x_{r}}{\rho_{o} \kappa_{r}\left(x_{r}+x_{s}\right)} \\
B C_{P} & =\frac{\varphi P_{\text {mill }} x_{b}}{\kappa_{b}\left[\rho_{o}\left(x_{r}+x_{s}\right)+\rho_{b} x_{b}\right]},
\end{aligned}
$$

where $\kappa_{r}$ and $\kappa_{b}(\mathrm{kWh} / \mathrm{t})$ represent the energy requirement for the abrasion of rocks and balls, respectively. The mill power draw model described in Apelt et al. (2001) is used to define $P_{\text {mill }}$. 
Table 3: Model parameter values.

\begin{tabular}{ccll}
\hline Parameter & Value & Unit & Description \\
\hline$\alpha_{r}$ & 0.47 & - & Fraction of rock in feed ore \\
$d_{H}$ & 88 & $1 / \mathrm{h}$ & Constant mill discharge parameter \\
$D_{m}$ & 4.07 & $\mathrm{~m}$ & Mill inside diameter $\left(D_{m}=2 r_{m}\right)$ \\
$\varepsilon_{s v}$ & 0.6 & - & Max fraction solids by volume of slurry at zero slurry flow \\
$\phi_{c}$ & 0.72 & - & Fraction of critical mill speed \\
$g$ & 9.8 & $\mathrm{~m}^{2} / \mathrm{s}$ & Gravity constant \\
$\kappa_{b}$ & 90 & $\mathrm{kWh} / \mathrm{t}$ & Steel ball abrasion energy requirement \\
$\kappa_{r}$ & 6.72 & $\mathrm{kWh} / \mathrm{t}$ & Rock abrasion energy requirement \\
$k_{P}$ & 0.97 & - & Power draw fitting parameter \\
$L_{c}$ & 0 & $\mathrm{~m}$ & Mill cone length \\
$L_{m}$ & 4.54 & $\mathrm{~m}$ & Mill cylinder length \\
$P_{N L}$ & 93.73 & $\mathrm{~kW}$ & Mill power at zero load \\
$\rho_{b}$ & 7.85 & $\mathrm{t} / \mathrm{m}^{3}$ & Steel ball density \\
$\rho_{o}$ & 3.2 & $\mathrm{t} / \mathrm{m}^{3}$ & Ore density \\
$\rho_{w}$ & 1 & $\mathrm{t} / \mathrm{m}^{3}$ & Water density \\
$r_{t}$ & 0.46 & $\mathrm{~m}$ & Mill feed trunnion radius \\
$V_{c s}$ & 96.9 & $\mathrm{~m}^{3} / \mathrm{h}$ & Flow of classifier solids to mill \\
$V_{c w}$ & 112 & $\mathrm{~m}^{3} / \mathrm{h}$ & Flow of classifier water to mill \\
$v_{m i l l}$ & 59.12 & $\mathrm{~m}^{3}$ & Mill volume \\
\hline
\end{tabular}

Finally, the plant model is written as

$$
\begin{aligned}
& \dot{x}=f_{P}(x, u)= {\left[\begin{array}{l}
V_{w i}-\varphi d_{H} x_{w}\left(\frac{x_{w}}{x_{s}+x_{w}}\right) \\
V_{s i}-\varphi d_{H} x_{w}\left(\frac{x_{s}}{x_{s}+x_{w}}\right)+\frac{\varphi P_{m i l l} x_{r}}{\rho_{o} \kappa_{r}\left(x_{r}+x_{s}\right)} \\
V_{r i}-\frac{\varphi P_{m i l l} x_{r}}{\rho_{o} \kappa_{r}\left(x_{r}+x_{s}\right)} \\
V_{b i}-\frac{\varphi P_{m i l l} x_{b}}{\kappa_{b}\left[\rho_{o}\left(x_{r}+x_{s}\right)+\rho_{b} x_{b}\right]}
\end{array}\right] } \\
& y=h_{P}(x, u)=\left[\begin{array}{l}
\frac{x_{w}+x_{s}+x_{r}+x_{b}}{v_{m i l l}} \\
\varphi d_{H} x_{w} \\
\frac{\rho_{o} x_{s}+\rho_{w} x_{w}}{x_{s}+x_{w}}
\end{array}\right]
\end{aligned}
$$

where $y=\left[J_{T}, Q, \rho_{Q}\right]^{T}$.

\subsection{Simulation Environment}

Table 3 shows the plant model parameter values and Table 4 shows the initial conditions considered. The data is adapted from the industrial data in Le Roux et al. (2013) for a single-stage closed grinding mill circuit.

\subsubsection{Plant and Observer}

The general simulation environment for the plant and observer is as follows:

(i.) The plant is integrated using the fourth order Runge-Kutta method at a rate of $T_{s}=2 \mathrm{~s}$. The full simulation time is $8 \mathrm{~h}$.

(ii.) Measurements are sampled at a rate of $T_{s}=2 \mathrm{~s}$.

(iii.) There is no feedback controller for the mill. For the sake of experimentation, it is assumed the flow from the classifier to the mill remains constant throughout the simulation.

(iv.) The plant is excited by sinusoidally varying input $M I W$ with a period of $T_{M I W}=12$ min and an amplitude of $8 \mathrm{~m}^{3} / \mathrm{h}$ around its initial condition. Since the amplitude is greater than the initial condition, the additional bound $M I W \geq 0 \mathrm{~m}^{3} / \mathrm{h}$ is considered. 
Table 4: Initial operating conditions.

\begin{tabular}{cccl}
\hline Variable & Value & $\sigma$ & \multicolumn{1}{c}{ Unit } \\
\hline \hline \multicolumn{5}{c}{ Inputs and } & Outputs \\
\hline$M I W$ & 4.64 & - & $\mathrm{m}^{3} / \mathrm{h}$ \\
$M F O$ & 65.2 & - & $\mathrm{t} / \mathrm{h}$ \\
$M F B$ & 5.68 & - & $\mathrm{t} / \mathrm{h}$ \\
$J_{T}$ & 0.33 & 0.006 & - \\
$Q$ & 234 & 5 & $\mathrm{~m}^{3} / \mathrm{h}$ \\
$\rho_{Q}$ & 2.10 & 0.02 & $\mathrm{t} / \mathrm{m}^{3}$ \\
\hline \multicolumn{5}{c}{ Plant Initial } & States \\
\hline$x_{b}$ & 8.23 & 0.04 & $\mathrm{~m}^{3}$ \\
$x_{r}$ & 1.88 & 0.01 & $\mathrm{~m}^{3}$ \\
$x_{s}$ & 4.65 & 0.02 & $\mathrm{~m}^{3}$ \\
$x_{w}$ & 4.63 & 0.02 & $\mathrm{~m}^{3}$ \\
\hline
\end{tabular}
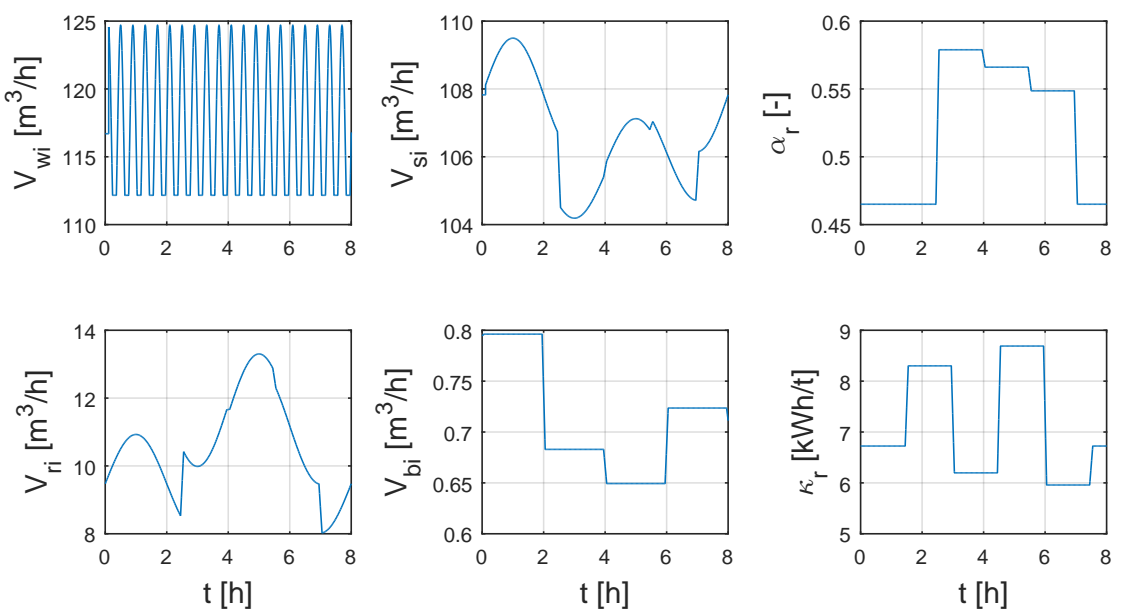

Figure 4: Inputs as described in (1), and disturbances for simulation scenarios.

(v.) To show the ability of the observer to track changes in $x_{s}$, and $x_{r b}$, inputs $M F O$ and $M F B$ are varied. Input $M F O$ is sinusoidally varied at a period of $T_{M F O}=4 \mathrm{~h}$ and an amplitude of $10 \mathrm{t} / \mathrm{h}$. Step changes at intervals of $2 \mathrm{~h}$ are applied to $M F B$ where the deviations from the operating point are chosen from the uniform distribution $\mathcal{U} \sim(-1,1)(\mathrm{t} / \mathrm{h})$.

(vi.) Disturbances in the feed-ore size-distribution and the feed-ore hardness are simulated by varying $\alpha_{r}$ and $\kappa_{r}$ around their nominal values.

- A change in feed size distribution is simulated by applying step-changes to $\alpha_{r}$ at intervals of $1.5 \mathrm{~h}$ starting at $t=2.5 \mathrm{~h}$. The size of step-changes are randomly selected from the uniform distribution $\mathcal{U}(-0.14,0.14)$. It is assumed measurement instrumentation is available to measure $\alpha_{r}$ at the input of the plant (Wei and Craig, 2009b).

- A change in feed ore hardness is simulated by applying step-changes to $\kappa_{r}$ at intervals of $1.5 \mathrm{~h}$ starting at $t=1.5 \mathrm{~h}$. The size of step-changes are randomly selected from the uniform distribution $\mathcal{U}(-2,2)(\mathrm{kWh} / \mathrm{t})$. This parameter is not measured.

Fig. 4 shows the inputs and disturbances to the plant. 


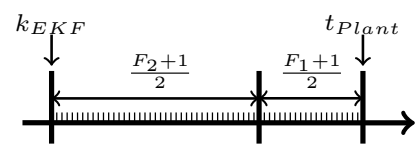

Figure 5: Filter implementation and management of phase shift.

\subsubsection{Simulation Scenarios}

Two simulation scenarios are considered.

Simulation 1. No measurement noise or process noise is added. Perfect measurements of the outputs in (26b) as well as the derivative of $\rho_{Q}$ is assumed and is passed to the observer, i.e. $R_{k}$ is small. The covariance matrix $Q_{k}$ is used as a tuning matrix. The initialization of the observer is:

$$
\begin{aligned}
& \text { - } \hat{x}_{0}=\left[3.5 \mathrm{~m}^{3}, 4 \mathrm{~m}^{3}, 9 \mathrm{~m}^{3}, 31 /\left(\mathrm{hm}^{3}\right), 10 \mathrm{~m}^{3} / \mathrm{h}\right]^{T} \\
& \text { - } P_{0}=\left(\operatorname{diag}\left[2 \mathrm{~m}^{3}, 2 \mathrm{~m}^{3}, 2 \mathrm{~m}^{3}, 21 /\left(\mathrm{hm}^{3}\right), 2 \mathrm{~m}^{3} / \mathrm{h}\right]\right)^{2} \\
& \text { - } Q_{k}=10^{-1} \times\left(\operatorname{diag}\left[0.2 \mathrm{~m}^{3}, 0.5 \mathrm{~m}^{3}, 1 \mathrm{~m}^{3}, 0.81 /\left(\mathrm{hm}^{3}\right), 2 \mathrm{~m}^{3} / \mathrm{h}\right]\right)^{2} \\
& \text { - } R_{k}=10^{-4} \times\left(\operatorname{diag}\left[1,1 \mathrm{~m}^{3} / \mathrm{h}, 1 \mathrm{t} / \mathrm{m}^{3}, 1 \mathrm{t} /\left(\mathrm{hm}^{3}\right)\right]\right)^{2}
\end{aligned}
$$

Simulation 2. Measurement noise $(v)$ is added to the outputs of the plant with a normal distribution of $\mathcal{N}\left(0, \sigma_{v}^{2}\right)$. System noise $(w)$ is added to the plant states with a normal distribution of $\mathcal{N}\left(0, \sigma_{w}^{2}\right)$. The values $\sigma_{v}$ and $\sigma_{w}$ are shown in Table 4 .

The covariance matrix $R_{k}$ for the EKF aligns with the covariance of the measurement noise added to the plant outputs. A high covariance is assigned to the measurement of $\dot{\rho}_{Q}$ as this measurement is highly sensitive to the noise on $\rho_{Q}$. The covariance matrix $Q_{k}$ is used as a tuning matrix. The initialization of the observer is:

$$
\begin{aligned}
& \text { - } \hat{x}_{0}=\left[3.5 \mathrm{~m}^{3}, 4 \mathrm{~m}^{3}, 9 \mathrm{~m}^{3}, 31 /\left(\mathrm{hm}^{3}\right), 10 \mathrm{~m}^{3} / \mathrm{h}\right]^{T} \\
& \text { - } P_{0}=\left(\operatorname{diag}\left[2 \mathrm{~m}^{3}, 2 \mathrm{~m}^{3}, 2 \mathrm{~m}^{3}, 21 /\left(\mathrm{hm}^{3}\right), 2 \mathrm{~m}^{3} / \mathrm{h}\right]\right)^{2} \\
& \text { - } Q_{k}=\left(\operatorname{diag}\left[0.1 \mathrm{~m}^{3}, 0.1 \mathrm{~m}^{3}, 0.1 \mathrm{~m}^{3}, 0.21 /\left(\mathrm{hm}^{3}\right), 2 \mathrm{~m}^{3} / \mathrm{h}\right]\right)^{2} \\
& \text { - } R_{k}=\left(\operatorname{diag}\left[0.006,5 \mathrm{~m}^{3} / \mathrm{h}, 0.02 \mathrm{t} / \mathrm{m}^{3}, 1.0 \mathrm{t} /\left(\mathrm{hm}^{3}\right)\right]\right)^{2}
\end{aligned}
$$

For the second simulation scenario where noise is added, the noisy measurements are filtered using a Savitzky-Golay digital filter. The filter smooths data by fitting a frame of $F$ data samples with polynomials of small order $N$ by means of linear least squares. The filter returns a filtered value at the centre of the frame. For real-time applications this means that the value returned by the filter is delayed by half the frame length $((F+1) / 2)$. To minimise this time delay, two consecutive filters are used.

1. The three measurements described in $(26 \mathrm{~b})$ are filtered with a filter configured to fit a polynomial of order 2 using a frame length of $F_{1}=35$ samples.

2. The first order derivative $\dot{\rho}_{Q}$ is calculated from the delayed filtered $\rho_{Q}$ data. A Savitzky-Golay filter with an order of 2 and a frame length of $F_{2}=135$ is used.

As depicted in Fig. 5, the filtered measurements are delayed by 18 samples from the current sample. Because $\dot{\rho}_{Q}$ is calculated from the filtered data, another 68 samples delay is introduced. The equivalent delay is 86 samples, i.e. $172 \mathrm{~s}$.

\section{Results and Discussion}

\subsection{Simulation Scenario 1}

The results of the simulation scenario where perfect measurements and no process noise are assumed is shown in Figs. 6 and 7. As seen from Fig. 7, the filter converges within two hours to the correct state value and is able to track the changes in the states. The effect of the disturbances in parameter $\kappa_{r}$ given in Fig. 4, which affects the generation of solids, is clearly visible in the abrupt changes of $\chi$ in Fig. 7, which represents the generation of solids. 

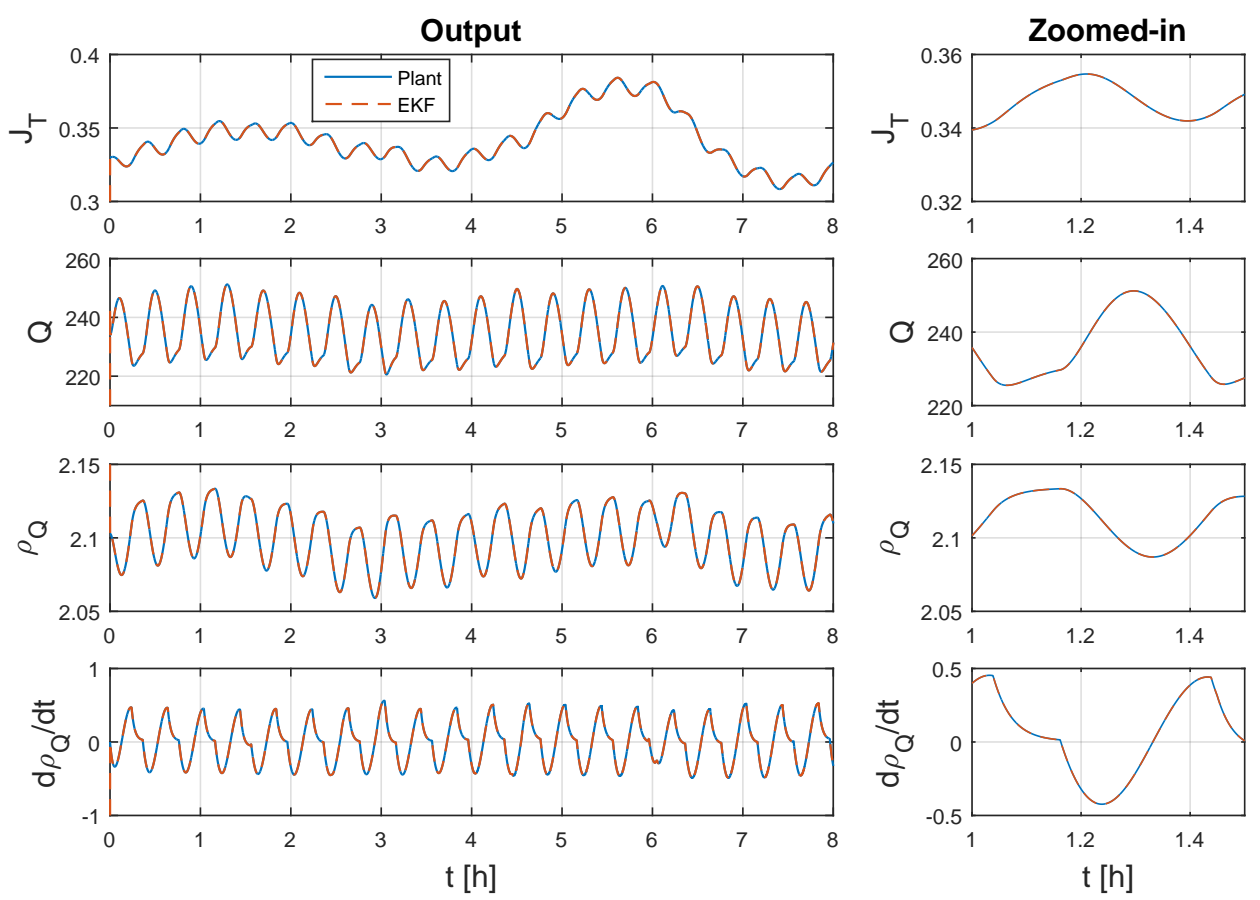

Figure 6: Output for Simulation Scenario 1.
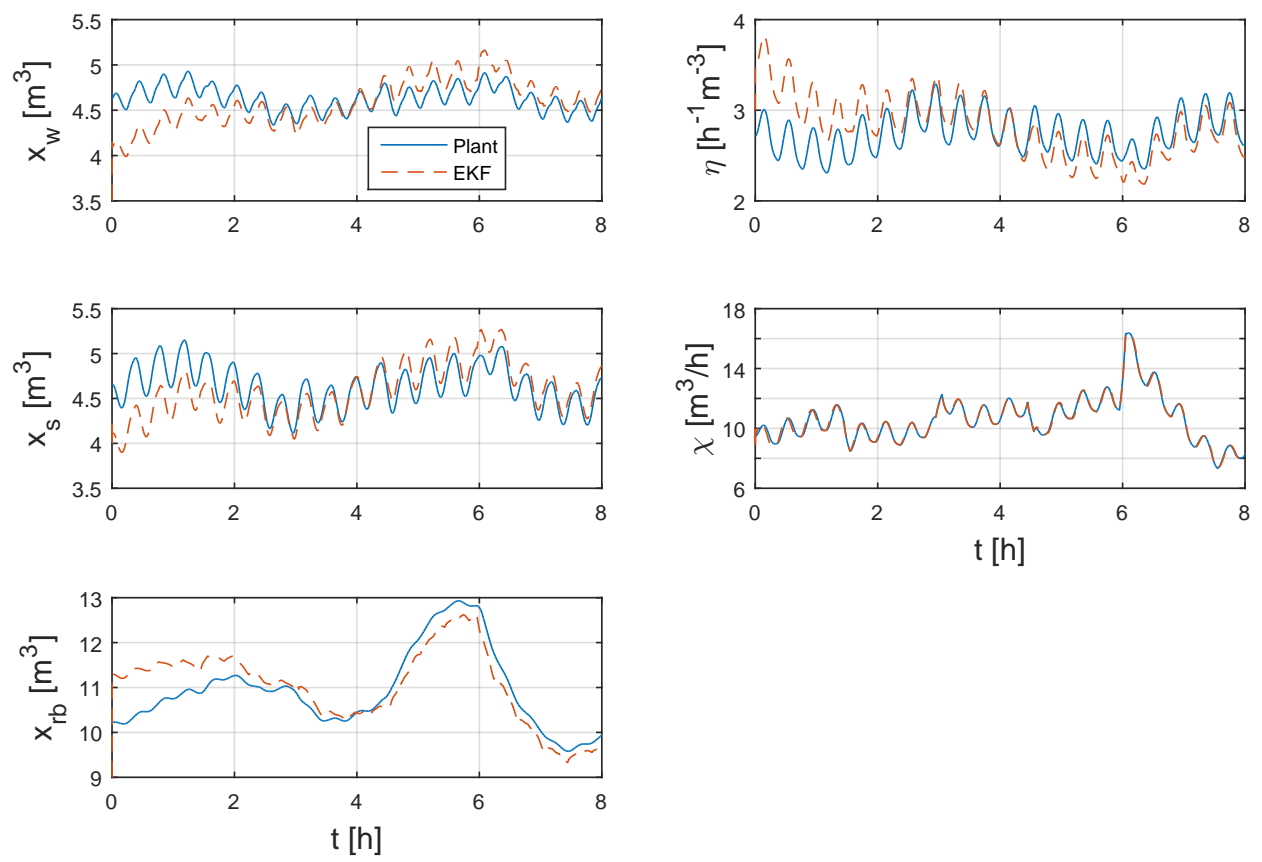

Figure 7: States and parameters for Simulation Scenario 1. 

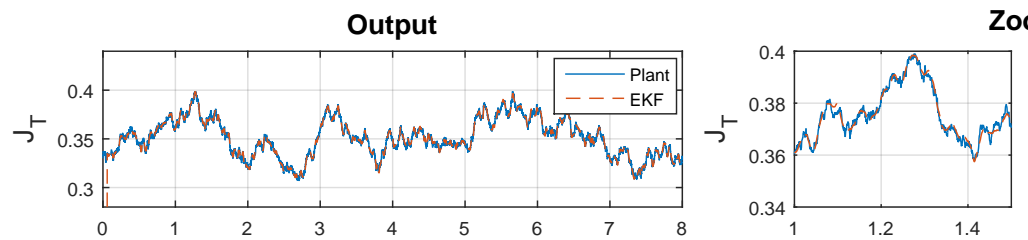

Zoomed-in
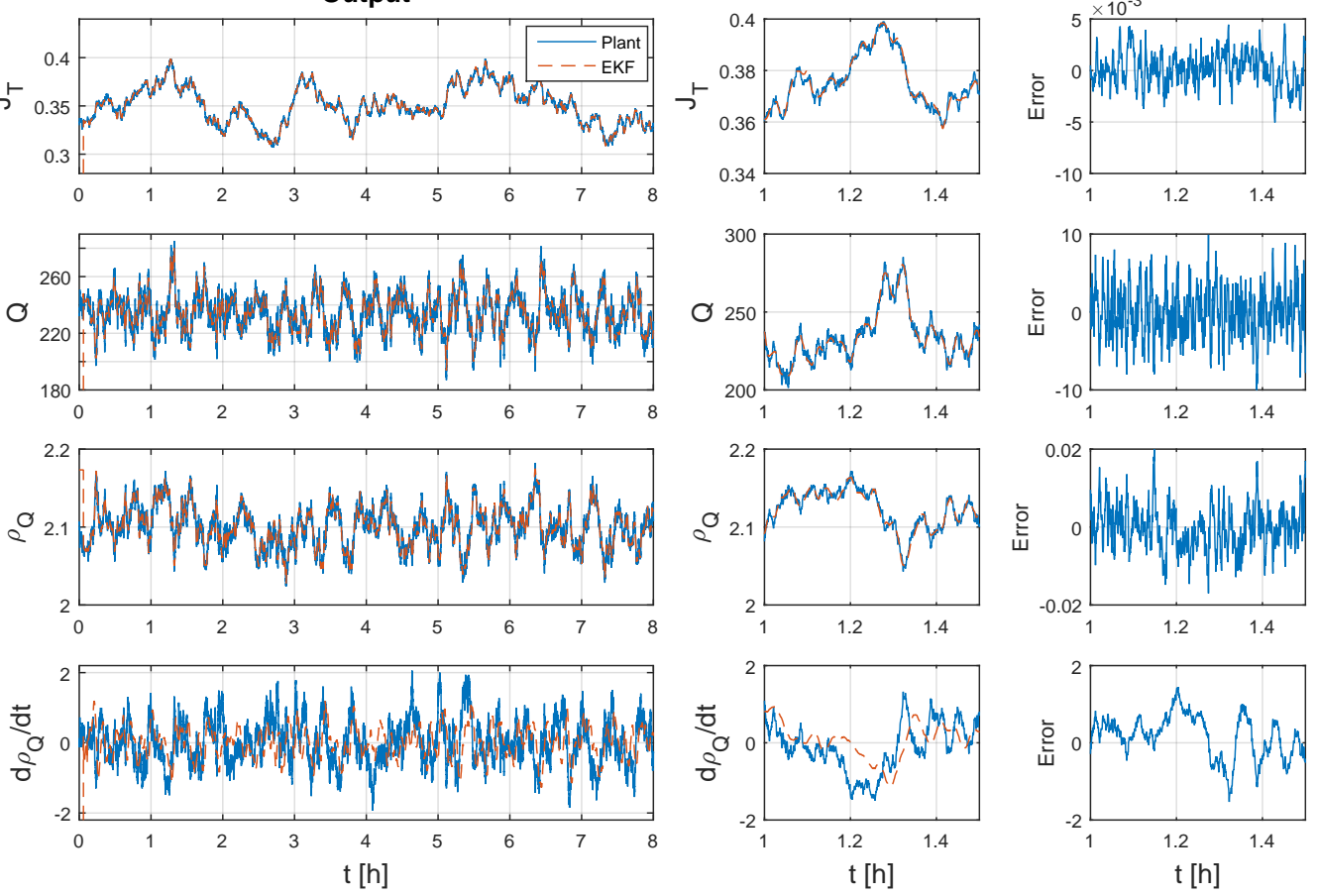

Figure 8: Output for Simulation Scenario 2. The error shown in the last column is the difference between the EKF output and the plant output.

\subsection{Simulation Scenario 2}

The results of the simulation scenario where measurements are filtered to remove noise and to calculate the derivative of $\rho_{Q}$ is shown in Figs. 8 and 9. As seen in Fig. 8, the noise on the measurements of $J_{T}$, $Q$ and $\rho_{Q}$ are filtered very well, but the derivative of $\rho_{Q}$ is not calculated with sufficient accuracy by the Savitzky-Golay filter. The error between the filtered value and the plant output is shown in the last column of Fig. 8. The error in $\dot{\rho}_{Q}$ is almost as large as the signal itself.

Since a Savitzky-Golay filter is based on a smoothing least-squares approximation of the signal, the filter cannot guarantee complete noise suppression in high frequencies when calculating the derivative of the signal. The size of the ripples at high frequencies in the magnitude response of the filter can be reduced only if a very long window length is chosen (Luo et al., 2005). However, a long window length introduces a time delay (phase shift) which is also undesirable.

The normalised root mean squared error (NRSME) between the actual state and the estimated state in Fig. 9 is shown in Table 5 and calculated as

$$
N R M S E=\frac{1}{\bar{\Lambda}} \sqrt{\frac{\sum^{N}(\Lambda-\hat{\Lambda})^{2}}{M}}
$$

where $\Lambda$ is the process signal, $\bar{\Lambda}$ is the mean of the process signal, $\hat{\Lambda}$ is the estimate of the process signal, and $M$ is the number of data points. Results in Fig. 9 and Table 5 indicate the EKF filter is able to track $x_{r b}$ with reasonable accuracy, where $x_{w}$ and $x_{s}$ are estimated with lower accuracy. Parameters $\chi$ and $\eta$ are used to absorb the uncertainties in the measured data. 

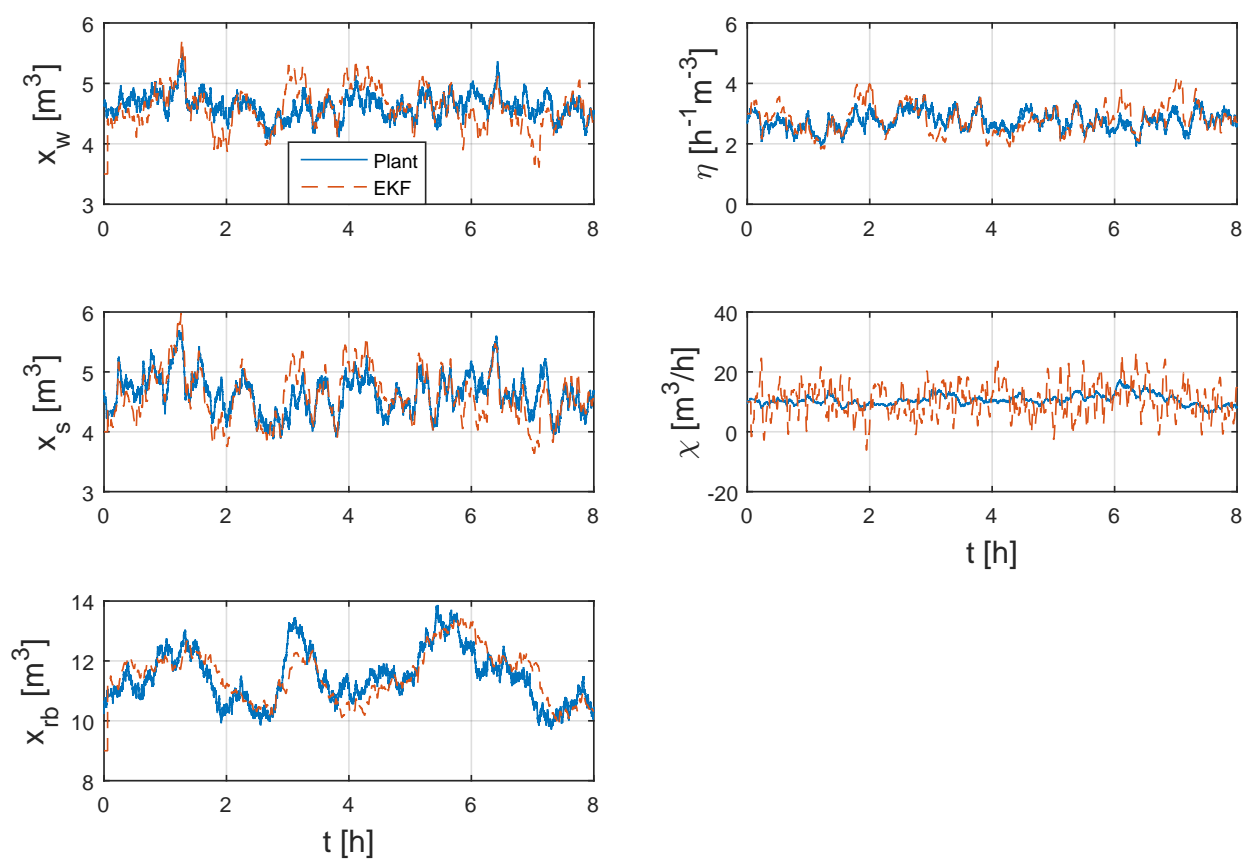

Figure 9: States and parameters for Simulation Scenario 2.

Table 5: Normalised Root Mean Squared Error of State Estimation.

\begin{tabular}{llllll} 
NRMSE & $6.66 \%$ & $6.17 \%$ & $5.14 \%$ & $12.9 \%$ & $53.3 \%$ \\
\hline
\end{tabular}

\section{Conclusion}

The states and parameters of a non-linear grinding mill observer model developed in this paper are weakly non-linearly observable, although they are not observable in the linearised case. For linear observability, a reduced observer model was developed. This reduced model represents the constituents of the mill using three states: water, solids, and grinding media (sum of rocks and balls). The grinding environment is modelled using two parameters: a discharge rate and an accumulation rate of solids. The measurement used are: the mill filling volume, the discharge rate of the mill, the discharge density of the mill, and the first time derivative of the discharge density.

Milling data is generated from a model different to the observer model. Simulations indicate that with accurate mill discharge measurements it is possible to estimate the system states and parameters using a discrete-time EKF. The main challenge is to accurately calculate the first time derivative of the mill discharge density.

Since industrial mills rarely include measurement instrumentation at the mill discharge, this work aims to motivate accurate discharge measurements in light of the information about mill inventories that can be gained. This would require careful consideration of mill discharge trommel designs to allow sufficient space to install the required instrumentation. Future work involves using the observer to provide state feedback for an advanced process controller for a grinding mill circuit.

\section{Acknowledgement}

The first author gratefully appreciates support from the University of Pretoria postgraduate study abroad bursary program. The second author gratefully acknowledges financial support provided by the Austrian 
Academy of Sciences in the form of an APART-fellowship at the Automation and Control Institute of Vienna University of Technology. The third author gratefully acknowledges financial support provided by the Austrian Federal Ministry of Science, Research and Economy, and the National Foundation for Research, Technology and Development. The fourth author would like to acknowledge the support of the National Research Foundation of South Africa (Grant No. 90533).

\section{References}

Amestica, R., Gonzalez, G. D., Barria, J., Magne, L., Menacho, J., Castro, O., 1993. A SAG mill circuit dynamic simulator based on a simplified mechanistic model. In: Proceedings XVIII International Mineral Processing Congress, Sydney, Australia. pp. $117-129$.

Amestica, R., Gonzalez, G. D., Menacho, J., Barria, J., March 1996. A mechanistic state equation model for semiautogenous mills. Int. J. Mineral Process. 44-45, 349-360.

Apelt, T. A., Asprey, S. P., Thornhill, N. F., Feb. 2001. Inferential measurement of SAG mill parameters. Minerals Eng. 14 (6), $575-591$.

Apelt, T. A., Asprey, S. P., Thornhill, N. F., 2002. Inferential measurement of SAG mill parameters II: State estimation. Minerals Eng. 15, 1043-1053.

Austin, L. G., 1990. Mill power equation for SAG mills. Minerals Metallurgical Process. 7 (1), 57-63.

Austin, L. G., Sutherland, D. N., Gottlieb, P., 1993. An analysis of SAG mill grinding and liberation tests. Minerals Eng. 6 (5), 491-507.

Chen, X., Li, Q., Fei, S., Aug. 2008. Constrained model predictive control in ball mill grinding process. Powder Tech. 186 (1), 31-39.

Chen, X., Zhai, J., Li, S., Li, Q., Sept. 2007. Application of model predictive control in ball mill grinding circuit. Minerals Eng. 20 (11), 1099-1108.

Coetzee, L. C., Craig, I. K., Kerrigan, E. C., January 2010. Robust nonlinear model predictive control of a run-of-mine ore milling circuit. IEEE Trans. Control Syst. Technol. 18 (1), 222-229.

Cortinovis, A., Mercangz, M., Mathur, T., Poland, J., Blaumann, M., 2013. Nonlinear coal mill modeling and its application to model predictive control. Control Eng. Practice 21, 308-320.

Craig, I., Aldrich, C., Braatz, R., Cuzzola, F., Domlan, E., Engell, S., Hahn, J., Havlena, V., Horch, A., Huang, B., Khanbaghi, M., Konstantellos, A., Marquardt, W., McAvoy, T., Parisini, T., Pistikopoulos, S., Samad, T., Skogestad, S., Thornhill, N., Yu, J., 2011. The impact of control technology: control in the process industries. T. Samad and A.M. Annaswamy (Eds.), Available at www.ieeecss.org. (Last access: 2015-11-18).

Craig, I., MacLeod, I., Jan. 1996. Robust controller design and implementation for a run-of-mine ore milling circuit. Control Eng. Practice 4 (1), 1-12.

Delaney, G. W., Cleary, P. W., Morrison, R. D., Cummins, S., Loveday, B., 2013. Predicting breakage and the evolution of rock size and shape distributions in AG and SAG mills using DEM. Minerals Eng. 50-51, 132-139.

Gupta, A., Yan, D. S., 2006. Mineral Processing Design and Operation: An Introduction. Elsevier B. V., Oxford, UK.

Herbst, J. A., Pate, W. T., 1999. Object components for comminution system softsensor design. Powder Tech. $105,424-429$.

Herbst, J. A., Pate, W. T., Oblad, A. E., 1992. Model-based control of mineral processing operations. Powder Tech. 69, $21-23$.

Herbst, J. S., Pate, W. T., 1996. On-line estimation of charge volumes in semi-autogenous and autogenous grinding mills. In: Proceedings of SAG 1996, Vancouver, B.C., Canada. pp. 817-827.

Herbst, J. S., Pate, W. T., Oblad, A. E., 1989. Experiences in the use of model-based expert control systems in autogenous and semi-autogenous grinding circuits. In: Proceedings of SAG 1989, Vancouver, B.C., Canada. pp. $669-686$.

Hermann, R., Krener, A. J., 1977. Nonlinear controllability and observability. IEEE Trans. Automatic Control AC-22 (5), $728-740$.

Hinde, A. L., Kalala, J. T., April 2009. The application of a simplified approach to modelling tumbling mills, stirred media mills and HPGR's. Minerals Eng. 22 (7-8), 633-641.

Hodouin, D., 2011. Methods for automatic control, observation and optimization in mineral processing plants. J. Process Control 21 (2), 211-225.

Hulbert, D. G., Craig, I. K., Coetzee, M. L., Tudor, D., 1990. Multivariable control of a run-of-mine milling circuit. J. South African Inst. Mining and Metallurgy 90 (7), 173-181.

King, R. P., 2001. Modeling and Simulation of Mineral Processing Systems. Butterworth-Heinemann, Oxford, UK.

Kojovic, T., Powell, M. S., Bailey, C., Drinkwater, D., 2011. Upgrading the JK SAG mill model. In: Int. Autogenous Grinding Semiautogenous Grinding High Pressure Grinding Rolls Tech. Conf., Vancouver (BC), Canada. pp. 1-20.

Latchireddi, S., Morrell, S., 2003. Slurry flow in mills: grate-only discharge mechanism (Part-1). Minerals Eng. 16, 625-633.

Le Roux, J. D., Craig, I. K., 2013. Reducing the number of size classes in a cumulative rates model used for process control of a grinding mill circuit. Powder Tech. 246, 169-181.

Le Roux, J. D., Craig, I. K., 2016. State and parameter identifiability of a nonlinear grinding mill circuit model. In: 17 th IFAC Symp. Mining Mineral Metal Processing. Vol. 49. Vienna, Austria, pp. 1-6.

Le Roux, J. D., Craig, I. K., Hulbert, D. G., Hinde, A. L., April 2013. Analysis and validation of a run-of-mine ore grinding mill circuit model for process control. Minerals Eng. 43-44, 121-134.

Le Roux, J. D., Olivier, L. E., Naidoo, M. A., Padhi, R., Craig, I. K., 2016a. Throughput and product quality control for a grinding mill circuit using non-linear MPC. J. Process Control 42, 35-50. 
Le Roux, J. D., Steinboeck, A., Kugi, A., Craig, I. K., 2016b. Nonlinear observability of grinding mill conditions. In: 17th IFAC Symposium Mining Mineral Metal Processing. Vol. 49. Vienna, Austria, pp. 13-18.

Luo, J., Ying, K., He, P., Bai, J., 2005. Properties of Savitzky-Golay digital differentiators. Digital Signal Processing 15 (2), $122-136$.

Mishra, B. K., 2003a. A review of computer simulation of tumbling mills by the discrete element method: Part I - contact mechanics. Int. J. Mineral Processing 71 (1-4), 73-93.

Mishra, B. K., Sept. 2003b. A review of computer simulation of tumbling mills by the discrete element method: Part II practical applications. Int. J. Mineral Process. 71 (1-4), 95-112.

Morrell, S., March 2004. A new autogenous and semi-autogenous mill model for scale-up, design and optimisation. Minerals Eng. 17 (3), 437-445.

Morrell, S., Stephenson, I., 1996. Slurry discharge capacity of autogenous and semi-autogenous mills and the effect of grate design. Int. J. Mineral Process. 46, 53-72.

Morrison, R. D., Shi, F. N., Whyte, R., 2007. Modelling of incremental rock breakage by impact - for use in DEM models. Minerals Eng. 20, 303-309.

Napier-Munn, T. J., Morrell, S., Morrison, R. D., Kojovic, T., 2005. Mineral Communition Circuits: Their Operation and Optimisation, 3rd Edition. JKMRC Monograph Series in Mining and Mineral Processing, Queensland, Australia.

Olivier, L. E., Huang, B., Craig, I. K., 2012. Dual particle filters for state and parameter estimation with application to a run-of-mine ore mill. J. Process Control 22 (4), 710-717.

Pomerleau, A., Hodouin, D., Desbiens, A., Gagnon, E., 2000. A survey of grinding circuit control methods: from decentralized PID controllers to multivariable predictive controllers. Powder Tech. 108 (2-3), 103-115.

Powell, M. S., Mainza, A. N., 2006. Extended grinding curves are essential to the comparison of milling performance. Minerals Eng. 19, 1487-1494.

Powell, M. S., Morrison, R. D., Oct. 2007. The future of comminution modelling. Int. J. Mineral Process. 84 (1-4), $228-239$.

Powell, M. S., van der Westhuizen, A. P., Mainza, A. N., June 2009. Applying grindcurves to mill operation and optimisation. Minerals Eng. 22 (7-8), 625-632.

Ramasamy, M., Narayanan, S. S., Rao, C. D. P., 2005. Control of ball mill grinding circuit using model predictive control scheme. J. Process Control 15 (3), 273-283.

Salazar, J., Valdez-Gonzalres, H., Vyhmesiter, E., Cubillos, F., 2014. Model predictive control of semi-autogenous mills. Minerals Eng. 64, 92-96.

Salazar, J. L., Magne, L., Acua, G., Cubillos, F., 2009. Dynamic modelling and simulation of semi-autogenous mills. Minerals Eng. 22 (1), 70-77.

Savitzky, A., Golay, M. J. E., 1964. Smoothing and differentiation of data by simplified least squares procedures. Analytical Chemistry 36 (8), 1627-1629.

Simon, D. J., 2006. Optimal State Estimation. John Wiley and Sons, Inc., Hoboken, United States.

Wei, D., Craig, I. K., 2009a. Economic performance assessment of two ROM ore milling circuit controllers. Minerals Eng. $22(9-10), 826-839$.

Wei, D., Craig, I. K., 2009b. Grinding mill circuits - A survey of control and economic concerns. Int. J. Mineral Process. $90(1-4), 56-66$.

Whiten, W. J., 1974. A matrix theory of communition machines. Chemical Eng. Sci. 29 (2), $589-599$.

Wills, B. A., 2006. Wills' Mineral Processing Technology: An Introduction to the Practical Aspects of Ore Treatment and Mineral Recovery, 7th Edition. Butterworth-Heinemann, Oxford, UK. 